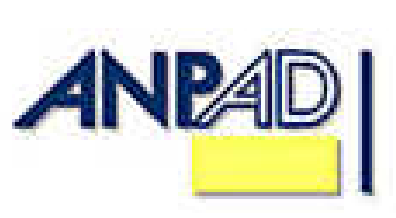

Disponível em

http://www.anpad.org.br/rac

RAC, Curitiba, v. 13, Edição Especial, art. 8, p. 121-138, Junho 2009

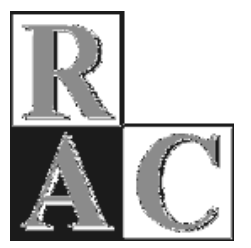

\title{
Inserção e Gestão do Trabalho de Pessoas com Deficiência: um Estudo de Caso
}

\author{
Insertion and Management of People with Disabilities at Work: a Case Study
}




\title{
RESUMO
}

O objetivo desta pesquisa foi analisar as possíveis relações entre as formas como os gestores vêem a deficiência, a adequação das condições de trabalho, e a satisfação das pessoas com deficiência em relação a aspectos relevantes para a manutenção da qualidade de vida no trabalho, em grande empresa brasileira que possui mais de mil funcionários portadores de deficiência, contratados. No referencial teórico foram utilizados os construtos de concepções de deficiência; adequação das condições e práticas de trabalho; e qualidade de vida no trabalho. A investigação empírica utilizou-se de metodologia quantitativa, por meio de estatística descritiva e correlação rho de Spearman; e qualitativa, por meio de análise de conteúdo das entrevistas. Os resultados confirmaram a existência de relações significativas entre as concepções de deficiência compartilhadas pelos gerentes e a adequação das condições e práticas de trabalho na organização. Além disso, foram constatadas implicações das concepções de deficiência e da adequação das condições e práticas de trabalho para a satisfação das pessoas com deficiência, principalmente no que se refere às possibilidades de carreira por parte dessas pessoas. Finalmente, também pôde ser verificada a potencialidade do modelo heurístico proposto para pesquisa.

Palavras-chave: diversidade; pessoas com deficiência; condições de trabalho; concepções de deficiência; qualidade de vida no trabalho.

\begin{abstract}
The aim of this research was to analyze the insertion and management of people with disabilities in a Brazilian enterprise with more than one thousand of these kinds of workers already hired, verifying the possible relations among the ways in which managers face the disability, the adequacy in practices and work conditions, and the satisfaction of disabled people towards the relevant aspects to maintain the Quality of Working Life. The theoretical references were conceptions of disability, actions of adequacy in practices and work conditions, and quality of working life. The presentation and analysis of data used Descriptive Statistics and Spearman correlation in a quantitative perspective and content analysis of interviews in a qualitative approach. The results confirmed significant relations between conceptions of disability and actions of adequacy in practices and work conditions. Moreover, implications of conceptions of disability and actions of adequacy in practices and work conditions were verified, mainly, concerning the satisfaction of people with disabilities related to the opportunity of personal growth in the job. Finally, the potential of the heuristic method proposed was proved.
\end{abstract}

Key words: diversity; people with disabilities; work conditions; conceptions of disability; quality of working life. 


\section{INTRODUÇÃO}

Os estudos sobre a inserção e gestão do trabalho de pessoas com deficiência incluem-se no campo de investigações sobre a diversidade que, nos últimos anos, se vem caracterizando como tema relevante dos estudos organizacionais. Contudo é um conceito que ainda carece de consenso entre os pesquisadores (Nkomo \& Cox, 1999). As definições variam num contínuo de uma perspectiva considerada restrita, que enfatiza a discriminação devido à raça, etnia, gênero e outros (Cross, Katz, Miller, \& Seashore, 1994), até uma definição bastante ampliada, que inclui todos, tendo por critério aspectos que diferenciam indivíduos e grupos (Jamieson \& O'Mara, 1991, dentre outros). Na presente pesquisa, a diversidade será contemplada em perspectiva restrita, considerando que seu foco será nas pessoas com deficiência.

Por outro lado, a Gestão da diversidade, como campo de estudos e práticas com vistas a gerenciar a diversidade dentro das organizações, surge e ganha contornos específicos no contexto do processo de globalização e fusão das empresas e em função da pressão de organismos internacionais ou de movimentos sociais. Conforme Alves e Galeão-Silva (2004), a gestão da diversidade se distingue das ações afirmativas, em função de duas variáveis: os grupos atingidos e os efeitos nas empresas. Na ação afirmativa, os grupos atingidos são as minorias e os grupos discriminados, e as mudanças provocadas nas empresas são decorrências de pressões coercitivas externas, como a lei de cotas. Na gestão da diversidade, são atingidas todas as diferentes identidades, e a diversidade passa a ser vista como vantagem competitiva para a organização.

Os estudos sobre a gestão da diversidade, com foco específico nas pessoas com deficiência, têm indicado três dificuldades para inserir e gerir o trabalho dessas pessoas: as formas como os gestores vêem a deficiência, a adequação das condições e práticas de trabalho por parte das empresas e a necessidade de avaliar a satisfação das pessoas com deficiência inseridas no mercado.

Várias pesquisas que analisam as dificuldades das pessoas com deficiência para se inserirem no mercado de trabalho têm concluído que existe falta acentuada de conhecimento em relação à capacidade de trabalho dessas pessoas e desconhecimento do que seja a deficiência (Anache, 1996; Carreira, 1997; Lancillotti, 2001; Mantoan, 1997; Oliveira, 1993). Também as pesquisas internacionais identificam a discriminação das pessoas com deficiência como dificuldades para o processo de inserção (Batavia \& Schriner, 2001; Henderson \& Bryan, 2004; Kamal, 2004; Popovich, Scherbaum, Scherbaum, \& Polinko, 2003; Stevens, 2002; Woodhams \& Danieli, 2000, dentre outros).

Além disso, pesquisas indicam a falta de preparo do mundo industrial para absorver as pessoas com deficiência, devido às adaptações em postos de trabalho que precisariam ser feitas nas organizações (Silva, 1993), à maior chance de se contratar pessoas com deficiência por parte de grandes empresas que tenham profissionais de Recursos Humanos (Goss, Goss, \& Adam-Smith, 2000) e à segregação das pessoas com deficiência em setores específicos das organizações (Batista, 2004).

Por outro lado, os estudos mostram que o trabalho associado a um emprego desempenha papel importante entre os grupos historicamente marginalizados, contribuindo para a diminuição das taxas de pobreza, do isolamento social e para o aumento da participação política desses grupos (Schur, 2002). Ademais, contribui para melhorar a percepção que as pessoas com deficiência têm de si mesmas (Carvalho-Freitas, Marques, \& Scherer, 2004; Martins, 1996; Oliveira, 1993). No entanto é necessário verificar, entre as pessoas com deficiência inseridas no mercado de trabalho, as formas como elas estão percebendo suas condições de trabalho.

Tendo como referência essas constatações, o objetivo desta pesquisa foi analisar as possíveis relações entre as formas como os gestores vêem a deficiência, a adequação das condições de trabalho e a satisfação das pessoas com deficiência em relação a aspectos relevantes para a manutenção da qualidade de vida no trabalho em uma empresa com grande número de pessoas com deficiência contratadas. 


\section{REFERENCIAL TEÓRICO}

Nesta seção, serão apresentados os construtos que subsidiaram a análise realizada, a saber: os construtos de concepções de deficiência, de adequação das condições e práticas de trabalho e de qualidade de vida no trabalho.

\section{Concepções de Deficiência}

Concepções de deficiência "são modos de pensamento construídos ao longo da história, não necessariamente fundados em informações e conhecimentos racionais, que oferecem os elementos utilizados para a qualificação das pessoas com deficiência e as justificativas para as ações em relação a elas" (Carvalho-Freitas, 2007, p. 36).

Por deficiência entende-se a alteração completa ou parcial de um ou mais segmentos do corpo humano, acarretando o comprometimento das funções física, auditiva ou visual. Em função de contingências históricas, sociais e espaciais, essa alteração poderá resultar em perda da autonomia para a pessoa, trazer problemas de discriminação social e dificultar a inserção social das pessoas com deficiência.

Essa definição de deficiência parte da perspectiva de que sua percepção tem natureza contingencial, isto é, depende das condições espaciais, históricas e sociais em que a pessoa com deficiência vive e trabalha (Freund, 2001; Kitchin, 1998; Omote, 1996).

Diversas reconstruções históricas sobre a deficiência já foram feitas, tanto na literatura nacional quanto na internacional: Aranha, 1995; Barnes, Mercer, \& Shakespeare, 2005; Goss et al., 2000; Henderson \& Bryan, 2004; Omote, 1996; Pessoti, 1984; Tregaskis, 2002, dentre outros. Essas reconstruções apresentam a natureza contingencial da deficiência. No entanto Carvalho-Freitas (2007) operacionalizou essa revisão histórica, construindo uma tipologia que identifica invariantes ou padrões que permanecem nas visões compartilhadas sobre a deficiência, mesmo quando o contexto histórico varia.

Utilizando-se de revisão histórica das formas de ver a deficiência ao longo do tempo, CarvalhoFreitas (2007) propõe quatro matrizes de interpretação da deficiência, para compor as sete concepções de deficiência que foram objeto de análise no presente estudo:

- A deficiência vista como fenômeno espiritual: as pessoas que percebem a deficiência nessa perspectiva atribuem uma origem metafísica à deficiência e tendem a considerá-la uma manifestação de desejos ou castigos divinos. A pessoa com deficiência, nesta matriz, é considerada como alguém que precisa ser mantida e cuidada, contribuindo para o surgimento de sentimentos de caridade e compaixão em relação a elas (Amiralian, 1986; Aranha, 1995; Bianchetti, 1998; Mantoan, 2004; Pessoti, 1984).

A normalidade como matriz de interpretação: as pessoas que compartilham dessa concepção têm na norma seu padrão de avaliação, sendo a deficiência considerada um desvio ou doença que necessita de cuidados especiais dos profissionais da saúde. Para as pessoas que possuem essa visão da deficiência, a possibilidade de inserção das pessoas com deficiência se dá mediante a reabilitação e a adequação delas ao sistema social (Bianchetti, 1998; Omote, 1995; Pessoti, 1984; Silva, 1993). Geralmente, as pessoas que compartilham dessa concepção consideram que as pessoas com deficiência assumem atitudes inadequadas no trabalho, provocando situações embaraçosas; são mais propensas a acidentes, têm problemas de relacionamento e devem ser lotadas em setores específicos da empresa. Além disso, consideram as instituições especializadas mais adequadas ao trabalho das pessoas com deficiência. 
A inclusão como matriz de interpretação: esta concepção é compartilhada pelas pessoas que deslocam sua percepção da deficiência de um problema individual para um problema social. $\mathrm{O}$ pressuposto compartilhado pelas pessoas que possuem essa visão da deficiência, é de que a sociedade tem de se adaptar para incluir todos, e a inclusão das pessoas com deficiência deve ser feita a partir de suas potencialidades (Barnes, 1999; Barnes, Oliver, \& Barton, 2002; Sassaki, 1999).

- A matriz de interpretação técnica da deficiência: materializa-se por meio da concepção das pessoas que vêem a diversidade como recurso a ser gerido nas organizações (Alves \& Galeão-Silva, 2004) e que consideram as práticas sociais e organizacionais como veículos para a participação e inclusão das pessoas com deficiência. Essa matriz se traduz em quatro fatores que, conforme Carvalho-Freitas (2007), avaliam as possibilidades de trabalho das pessoas com deficiência em relação às percepções explicitadas em seguida.

Percepção de desempenho: identifica a percepção das pessoas em relação ao desempenho, produtividade e qualidade de trabalho das pessoas com deficiência e suas implicações para a competitividade da empresa.

- Percepção do vínculo: focaliza a percepção das pessoas em relação ao comprometimento e estabilidade no emprego das pessoas com deficiência.

- Percepção dos benefícios da contratação: identifica a percepção do impacto da contratação de pessoas com deficiência para a imagem da empresa junto a funcionários e clientes e também para o clima da organização.

- Percepção sobre a necessidade de treinamento: indica a percepção quanto à necessidade de treinamento das chefias e funcionários para a inserção de pessoas com deficiência na empresa.

\section{As Ações de Adequação das Condições e Práticas de Trabalho}

As ações de adequação das condições e práticas de trabalho são elementos cuja presença ou ausência modificam a relação de forças entre pessoas com e sem deficiência nas organizações. Contemplam tanto modificações no espaço concreto de trabalho quanto implementações de práticas específicas que visam dar condições de igualdade no trabalho às pessoas com deficiência (Carvalho-Freitas, 2007).

Três fatores referentes às ações de adequação das condições e práticas de trabalho foram utilizados no estudo empírico (Carvalho-Freitas, 2007).

- Fator 1 - Sensibilização: este fator focaliza a percepção das pessoas em relação às ações da empresa no sentido de sensibilizar as chefias e funcionários para a inserção de pessoas com deficiência e fornecer informações sobre saúde e segurança no trabalho às pessoas com deficiência contratadas.

- Fator 2 - Adaptações: este fator identifica a percepção das pessoas em relação às adaptações nas condições e instrumentos de trabalho, realizadas pela empresa, para facilitar a inserção de pessoas com deficiência.

- Fator 3 - Práticas de RH: este fator indica a percepção das pessoas em relação à adequação das práticas de seleção, treinamento, promoção e transferência, realizadas pela empresa, com vistas a inserir as pessoas com deficiência.

Esses fatores foram identificados por meio da revisão da literatura sobre a questão do espaço na perspectiva sociológica (Bourdieu, 1996, 2000; Freund, 2001; Kitchin, 1998) e das indicações da Agência Européia para a Segurança e a Saúde no Trabalho (2004), quanto aos aspectos a serem analisados para garantir a inserção de pessoas com deficiência no mercado de trabalho. 


\section{Qualidade de Vida no Trabalho}

Avaliando-se as contribuições dos diversos pesquisadores que investigam a qualidade de vida no trabalho e retomando um dos objetivos desta pesquisa, que consiste em verificar a satisfação das pessoas com deficiência em relação a aspectos relevantes para a manutenção da qualidade de vida no trabalho, optou-se por trabalhar com o modelo de Walton (1973). Esse modelo foi utilizado por se considerar que sua perspectiva está mais alinhada com as preocupações desta pesquisa, colocando a questão da qualidade de vida em contexto que busca regulamentar os direitos de minorias e assegurar saúde, segurança e garantia no trabalho, fatores considerados essenciais para a inserção de pessoas com deficiência no mercado de trabalho.

Para Walton (1973), a denominação qualidade de vida no trabalho (QVT) está inserta no contexto das relações de trabalho desde o início do século XX, na busca da legalização das condições das mulheres e das crianças, da regulamentação dos direitos e das lutas do movimento sindical para assegurar saúde, segurança e garantia no trabalho. Esse autor discute a amplitude do conceito e a dificuldade de isolar e identificar os atributos que interferem na qualidade de vida no trabalho. Propõe, então, oito categorias, ou indicadores, que, segundo ele, contemplariam o construto:

a) Compensação justa e adequada (remuneração): significa eqüidade interna e externa tanto em termos de salário direto quanto indireto (benefícios).

b) Condições de segurança e saúde no trabalho (condições de trabalho): implicam condições de trabalho que assegurem a manutenção da segurança e da saúde do trabalhador, envolvendo a jornada e a carga de trabalho, equipamentos disponibilizados para a execução do trabalho e ambiente saudável (preservação da saúde do trabalhador).

c) Uso e desenvolvimento de capacidades: implica o aproveitamento do talento humano, isto é, significa autonomia, uso de habilidades variadas e participação no processo total de trabalho.

d) Oportunidade de crescimento e segurança (oportunidades de crescimento profissional): implica a possibilidade de desenvolver carreira e ter segurança quanto à manutenção do trabalho, isto é, abarca as políticas da instituição relacionadas ao desenvolvimento, crescimento e segurança de seus empregados.

e) Integração social na organização: significa apoio dos grupos primários, igualdade de oportunidades, ausência de preconceitos e cultivo ao bom relacionamento.

f) Constitucionalismo (direitos na instituição): significa garantia no cumprimento das normas e procedimentos que se relacionem às leis e direitos trabalhistas, respeito à privacidade, liberdade de expressão e adesão a padrões de igualdade.

g) Trabalho e espaço total da vida (equilíbrio trabalho e vida): possibilidade de equilibrar o tempo e a energia dedicados à empresa e aos demais espaços da vida.

h) Relevância do trabalho na vida (relevância do trabalho): investiga-se a percepção do empregado em relação à imagem da empresa, à responsabilidade social da instituição na comunidade e à relevância do trabalho desempenhado.

\section{MÉTODO}

A pesquisa constituiu-se de um estudo de caso realizado em grande instituição de serviços e intermediação financeira, que possui cerca de 1.400 funcionários com deficiência em seu quadro de pessoal; funcionários com deficiência física, visual ou auditiva sem comprometimento intelectual, conforme interesse da pesquisa. 
A escolha da empresa se deveu ao grande número de pessoas com deficiência que possuía em seu quadro de pessoal e à disponibilidade da empresa em participar da pesquisa.

A coleta de dados ocorreu no ano de 2006. Participaram da pesquisa três regionais da empresa: a Regional Minas, a Regional Bahia e a Regional Paraná. Os resultados do teste de qui-quadrado indicaram que as diferenças entre as frequiências de respondentes que concordavam ou discordavam em relação aos construtos analisados não foram consideradas significativas em relação ao Estado de origem dos respondentes. O único fator que apresentou diferença significativa entre os Estados a que pertenciam as regionais da empresa foi o fator sensibilização (valor qui-quadrado $=7,941$, com nível de significância $=0,01$ e valor $\mathrm{p}=0,019$ ).

A pesquisa se constituiu de duas etapas.

a) $\mathrm{Na}$ primeira, com foco quantitativo, os gerentes de pessoas com deficiência e responsáveis pelo programa de inserção da empresa responderam aos Inventários de Concepção de Deficiência e Ações de Adequação das Condições e Práticas de Trabalho, totalizando 80 gestores $(94 \%$ deles com formação superior), sendo $28 \%$ do Paraná, $51 \%$ de Minas Gerais e $21 \%$ da Bahia. Além disso, 128 pessoas com deficiência responderam ao Questionário de Qualidade de Vida no Trabalho, sendo 31\% da Bahia, 43\% de Minas Gerais e 25\% do Paraná. Dessas pessoas com deficiência, $76 \%$ eram portadoras de deficiência física, $14 \%$ de deficiência visual e $10 \%$ de deficiência auditiva, sendo que $82 \%$ estavam fazendo ou já haviam concluído formação de nível superior.

b) Na segunda etapa da pesquisa, com foco qualitativo, foram entrevistadas 11 pessoas com deficiência que trabalhavam nas unidades sediadas em Belo Horizonte, 11 gerências que trabalhavam diretamente com as pessoas com deficiência entrevistadas e cinco funcionários da área de Gestão de Pessoas que atuavam no programa de inserção de pessoas com deficiência da empresa: havia 25 pessoas com deficiência, distribuídas em 25 unidades diferentes na cidade de Belo Horizonte. A amostra foi constituída a partir de critérios de diversidade, em função de variáveis consideradas estratégicas para o estudo, quais sejam, diferentes tipos de deficiência (física, visual e auditiva) e diferentes unidades. O objetivo das entrevistas foi aprofundar as análises dos questionários, por meio de questões semi-estruturadas sobre concepções de deficiência, ações de adequação das condições e práticas de trabalho e satisfação com fatores da qualidade de vida no trabalho. A escolha das unidades de Belo Horizonte obedeceu a critérios de conveniência e factibilidade.

Foram analisados os resultados obtidos em cada fator dos três questionários utilizados, sendo usada a frequiência percentual dos dados para a análise descritiva.

Foi também verificado se havia correlações entre os fatores dos Inventários de Concepções de Deficiência e Ações de Adequação das Condições e Práticas de Trabalho, utilizando-se do coeficiente de correlação rho de Spearman, visando constatar se os fatores estavam associados e qual a direção e intensidade dessa associação, isto é, se a variação de um fator analisado estava relacionada com a variação de outro fator considerado na investigação; se a direção era positiva, quanto mais aumentava a concordância em relação a um fator, aumentava-se a concordância em relação ao outro fator; ou negativa, aumentando-se a concordância com um fator, diminuía-se a concordância com outro; e se as correlações eram intensas, isto é, mais próximas de +1 ou -1 . Considerando que a escala Likert adotada (discordo totalmente a concordo totalmente) não dispõe de propriedades de escalonamento intervalar ou de razão e pode não apresentar uma distribuição normal, a escolha pelo coeficiente rho de Spearman se configurou na decisão mais adequada (Malhotra, 2001).

As entrevistas duraram, em média, 40 minutos. Foram anotados os principais aspectos mencionados das questões durante a entrevista; no final, retomavam-se os principais pontos anotados e certificavase com o entrevistado se o entendimento das respostas estava adequado (validação subjetiva).

As análises das entrevistas foram realizadas tendo como referência o conteúdo das entrevistas, isto é, a posição das pessoas quanto aos aspectos pesquisados. Foi contemplada a frequiência de respostas de 
conteúdo similar, considerando a predominância quantitativa das posições das pessoas sobre as questões. As entrevistas foram ainda analisadas, considerando-se o contexto da empresa, enfatizando a "interpretação em contexto" (Lüdke \& André, 1986, p. 18), isto é, analisando as respostas em face das características específicas da empresa e em relação às práticas de inserção adotadas por ela.

Em conformidade com os objetivos deste estudo, foi hipotetizado um modelo heurístico de análise da inserção e gestão do trabalho de pessoas com deficiência na empresa, conforme se apresenta na Figura 1.

\section{Figura 1: Modelo Heurístico Hipotetizado para a Pesquisa}

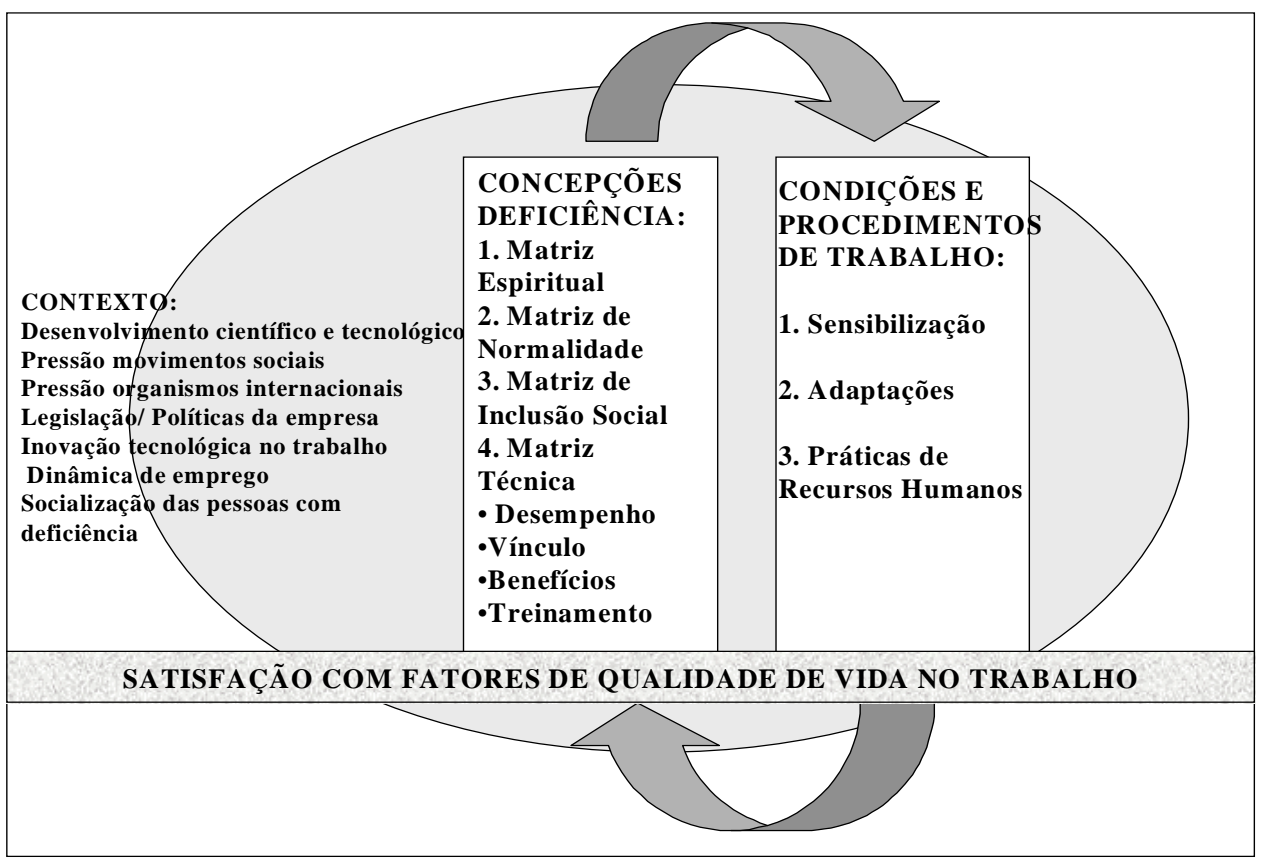

O modelo apresentado pressupõe que as dimensões de análise - concepções de deficiência e ações de adequação das condições e práticas de trabalho - estão insertas em contexto histórico e social que caracteriza a natureza contingencial da inserção e gestão do trabalho de pessoas com deficiência nas empresas, e que a satisfação das pessoas com deficiência com os fatores de qualidade de vida no trabalho está relacionada com todos esses fatores: contexto, concepções de deficiência e ações de adequação das condições e práticas de trabalho.

Além disso, o modelo pressupõe as seguintes relações

1) Existe correlação entre os fatores do construto concepções de deficiência e os fatores de ações de adequação das condições e práticas de trabalho.

2) As concepções de deficiência, ações de adequação das condições e práticas de trabalho e fatores de contexto influenciam, qualitativamente, a satisfação das pessoas com deficiência em relação aos fatores de qualidade de vida no trabalho.

\section{BREVE CARACTERIZAÇÃo DA EMPRESA}

Trata-se de grande empresa que vem buscando, desde 1999, sistematizar suas políticas e práticas de gestão da diversidade, visando garantir possibilidades reais de trabalho para as pessoas com deficiência. Busca cumprir a lei de cotas e também ser referência em responsabilidade socioambiental. 
Tem claramente definida sua política antidiscriminação, que proíbe qualquer procedimento que possa criar desvantagens para as pessoas com deficiência na empresa, evitando a identificação dessas pessoas mesmo nos cadastros da empresa.

Definiu como estratégia prioritária a adequação das unidades e dos postos de trabalho, visando possibilitar condições de trabalho adequadas às necessidades das pessoas com deficiência.

Seu processo de seleção já passou pelas adaptações necessárias para garantir a participação de todos, tais como: realização de provas em locais acessíveis, provas com letras ampliadas ou em computadores com softwares de voz para portadores de deficiência visual e aplicadores de provas de seleção bilíngüe capazes de comunicarem-se em Língua Brasileira de Sinais [LIBRAS].

Em princípio, são garantidas as mesmas oportunidades de treinamento e desenvolvimento, transferência e carreira para todos. Também já foram realizadas algumas atividades de sensibilização para a inserção de pessoas com deficiência, como divulgação de cartilhas informativas, programa na TV Corporativa sobre a inserção de pessoas com deficiência e orientações em relação à adequação das condições de trabalho por parte da equipe de Medicina e Segurança no Trabalho, conforme necessidade da Unidade da empresa.

\section{APRESENTAÇÃO E DISCUSSÃO dOS DADOS}

Os dados serão apresentados e analisados conforme cada construto utilizado: concepções de deficiência, ações de adequação das condições e práticas de trabalho e qualidade de vida no trabalho.

\section{Concepções de Deficiência}

Neste construto, serão analisadas: a concepção espiritual, a concepção baseada na normalidade, a concepção baseada nos pressupostos da inclusão, a percepção do desempenho, do vínculo, a percepção dos benefícios da contratação de pessoas com deficiência e a percepção sobre a necessidade de treinamento.

Verificou-se que $19 \%$ do total da amostra acreditam que a deficiência tenha uma origem metafísica, isto é, que seja proveniente de eleição ou castigo divino.

Durante a realização das entrevistas, dois gerentes explicitaram que atribuíam uma origem espiritual à deficiência, sendo sua manifestação, segundo eles, uma possibilidade de humanização e crescimento espiritual para as pessoas que convivem com a pessoa com deficiência. É importante sublinhar que um dos gerentes se emocionou bastante durante a realização da entrevista e, quando perguntado sobre as questões ligadas à matriz técnica de concepção da deficiência (desempenho, vínculo, benefícios da contratação e necessidade de treinamento), enfatizou muito que

"a pessoa com deficiência precisa ter o desempenho exigido, tem de contribuir, não deve ser apartada dos demais, pois eu entendo que a empresa faz todas as adaptações necessárias, pois espera que a pessoa com deficiência tenha um bom desempenho".

Quando questionado se o desempenho do seu subordinado era condizente com as expectativas da empresa - ter de contribuir, ter bom desempenho, isto é, se o discurso idealizado do ter de efetivamente ocorria no dia-a-dia de trabalho - o gerente se emocionou muito e disse que não gostaria de avaliar o desempenho de seu subordinado e que podia apenas garantir que sua parte - adequação das condições de trabalho - estava sendo feita. $\mathrm{O}$ outro gerente afirmou que "a gente acaba sendo mais paternalista com as pessoas com deficiência, acaba entendendo suas dificuldades". 
Essas entrevistas levam a crer que para esses gerentes o trabalho com pessoas com deficiência é mais conflituoso e com demandas diferenciadas e que futuras investigações são necessárias para elucidar as implicações de uma concepção espiritual da deficiência em locais de trabalho, onde os resultados são, por excelência, a premissa de avaliação do desempenho.

A análise dos dados revelou que $21 \%$ dos gestores consideram a deficiência como um desvio da normalidade e compartilham do pressuposto de que as pessoas com deficiência precisam ser separadas das demais, quer seja em setores específicos da empresa, quer seja em instituições especializadas.

As análises das entrevistas identificaram que a alocação de pessoas com deficiência é uma temática controvertida entre os gerentes e mesmo entre alguns profissionais que atuam com a inserção de pessoas com deficiência. Alguns gerentes falam da dificuldade maior em relação às pessoas com deficiências auditiva e visual e da necessidade de mantê-las em setores específicos, em função de suas deficiências e das exigências das funções disponíveis na empresa. Contudo outros gerentes discordam e afirmam que a carreira das pessoas com deficiência deve ser a mesma dos demais. Um gerente disse:

"Acho que a própria empresa pode incentivar problemas entre funcionários com e sem deficiência em função da alocação das pessoas com deficiência no trabalho. Acho que a alocação no trabalho não é intrínseca à deficiência, mas uma conseqüência da adequação do funcionário".

Essa temática também é objeto de controvérsias entre as pessoas com deficiência. Algumas afirmam que alguns setores são inadequados a elas, devido às suas deficiências; outras discordam; até mesmo ficam ressentidas, quando não acreditam que são capazes de realizar qualquer tipo de atividade.

Esses resultados indicam que ainda existe na empresa um foco na deficiência e suas limitações, mais que nas potencialidades das pessoas e em suas possibilidades, ocorrendo divergências em função da ausência de uma alocação negociada (junto com a pessoa com deficiência) nas funções disponíveis na empresa.

Em relação à concepção baseada em pressupostos da inclusão, $81 \%$ dos gestores têm assumido a posição de que é necessário modificar o ambiente de trabalho para este ser acessível a todos, o que é uma tendência na atualidade.

Em relação à percepção de desempenho, $92 \%$ dos gestores avaliam positivamente o desempenho das pessoas com deficiência. De forma geral, os entrevistados afirmam que as pessoas com deficiência têm desempenho similar ao das demais pessoas e que a inserção dessas pessoas não tem impacto negativo na competitividade da empresa.

No entanto, alguns gerentes disseram que o "desempenho depende muito das pessoas, elas são diferentes". Outro gerente confirma:

"Olha, a questão do desempenho das pessoas com deficiência depende muito das pessoas. Alguns tratam a própria deficiência como muleta e acham que têm de ter tratamento diferenciado. Há pessoas com deficiência que usam de esperteza. Já tive funcionário que mancava de uma perna e fazia corpo mole. Agora, há outros que são excelentes e que vêem o trabalho como uma oportunidade."

Além disso, existem muitas resistências iniciais, por ocasião da alocação de pessoas com deficiência em unidades que ainda não trabalharam com elas. Por outro lado, em unidades que têm pessoas com deficiência com bom desempenho, os gerentes perguntam: "Não tem como me mandar outra pessoa com deficiência como o fulano de tal?"

Em relação à percepção do vínculo das pessoas com deficiência em relação ao trabalho, os gestores se dividem; $42 \%$ concordam que as pessoas com deficiência são mais comprometidas que as demais e $58 \%$ afirmam não haver diferença entre pessoas com e sem deficiência no que se refere ao compromisso com o trabalho.

As entrevistas confirmam os resultados obtidos nos questionários. A maioria dos gerentes entrevistados afirmou que o vínculo das pessoas com deficiência é algo individual e que não 
consideram o vínculo com a empresa um fator que diferencia pessoas com e sem deficiência no trabalho. No entanto dois gerentes entrevistados e um profissional que atua na inserção de pessoas com deficiência afirmaram que consideram o comprometimento das pessoas com deficiência maior que o das demais, em função das poucas oportunidades existentes no mercado de trabalho.

Os resultados desse fator indicam que é necessário realizar novas investigações para analisar a questão do vínculo das pessoas com deficiência com o trabalho e o tipo de comprometimento predominante, visando retificar ou ratificar a crença popular de que o comprometimento das pessoas com deficiência é maior que o das demais pessoas no ambiente de trabalho.

Em relação à percepção dos benefícios da contratação de pessoas com deficiência, verificou-se que a maioria dos respondentes $(94 \%)$ concorda que a contratação de pessoas com deficiência beneficia a empresa, pela melhoria seja do clima interno, seja da imagem da empresa junto a clientes e funcionários.

Todas as pessoas entrevistadas (gerentes e profissionais de inserção) concordam em que a contratação de pessoas com deficiência beneficia a imagem da empresa junto a clientes e funcionários, principalmente porque é uma ação que, segundo eles, é coerente com a preocupação com a responsabilidade socioambiental da empresa. Compartilham o pressuposto de que a empresa tem papel relevante junto à sociedade, devendo ser um exemplo nesse tipo de ação. Com relação a possíveis benefícios em relação ao clima interno, três gerentes discordaram, afirmando que a contratação de pessoas com deficiência não tem impacto positivo ou negativo no clima da empresa.

Embora haja algumas discordâncias em relação aos benefícios da contratação de pessoas com deficiência para o clima da empresa, os entrevistados são unânimes quanto ao impacto positivo para a imagem da empresa, sublinhando a importância desse tipo de ação no âmbito das políticas de responsabilidade socioambiental da empresa.

Em relação à percepção sobre a necessidade de treinamento, $45 \%$ dos gestores discordam de que as chefias e os funcionários precisam ser treinados para trabalhar com pessoas com deficiência. Analisando os dados das entrevistas, verifica-se que a maioria dos gerentes afirma que não recebeu nenhum treinamento para a inserção e gestão do trabalho de pessoas com deficiência e que as informações recebidas foram por meio de cartilhas e informações contidas na intranet da empresa. Um gerente afirmou:

"Ainda existe muito preconceito em relação às pessoas com deficiência. O tratamento é respeitoso, mas, sendo bastante honesto, na maioria das vezes, as pessoas com deficiência não são consideradas quando existe uma vaga em caráter de promoção. Ainda existe esse tipo de preconceito, apesar de estar mudando.

Então, considero necessário esse tipo de treinamento."

Os resultados das análises dos questionários e das entrevistas indicam a ausência de treinamentos sistematizados e de discussões mais amplas sobre a inserção de pessoas com deficiência na empresa. Essa circunstância indica que, se essa temática não for objeto de reflexão e aprendizagem, pouco provavelmente as pessoas conseguirão diagnosticar suas próprias necessidades de treinamento, uma vez que a referência delas é apenas o cotidiano de trabalho com pessoas com deficiência, variando de pessoa para pessoa a capacidade de reflexão sobre sua própria ação.

\section{Ações de Adequação das Condições e Práticas de Trabalho}

Estão apresentadas, a seguir, as análises dos dados referentes às Ações de Adequação das Condições e Práticas de Trabalho: fatores de sensibilização, adequação das condições de trabalho e adequação das práticas de Recursos Humanos.

No fator de sensibilização, os resultados encontrados indicam que essas práticas não são atividades sistematizadas o suficiente na empresa, para que os respondentes possam afirmar com convicção que existam. Além disso, $41 \%$ dos respondentes afirmaram que não existem na empresa práticas de 
sensibilização das chefias e funcionários para o trabalho com pessoas com deficiência. Especificamente na Regional Minas Gerais, os resultados obtidos nos questionários são confirmados pelas entrevistas, que mostram que a maioria dos gerentes afirma acreditar haver as atividades de sensibilização mencionadas. Contudo confirmam que as atividades de sensibilização das chefias e funcionários consistiram apenas no acesso às cartilhas com informações genéricas sobre o assunto.

Em relação ao fator adequações das condições de trabalho, os resultados encontrados indicam uma tendência de adequação dessas condições por parte da empresa, o que é confirmado nas entrevistas e na própria observação dos locais de trabalho em que as entrevistas foram realizadas: $80 \%$ dos gestores afirmam ter havido modificação nas condições de trabalho, visando à inserção de pessoas com deficiência.

A informação recorrente em todas as entrevistas é que a empresa definiu uma política de adequação das condições de trabalho em todas as suas instalações; nas instalações novas, os prédios já são construídos conforme exigências legais e nos prédios antigos as adaptações são realizadas conforme a necessidade dos funcionários, tendo sido priorizadas as adaptações nos espaços em que os clientes tenham acesso. De todo modo, as atividades de adaptação têm sido priorizadas pela empresa não apenas das condições físicas de trabalho, mas também dos instrumentos e mobiliários necessários.

No fator práticas de Recursos Humanos, a análise dos resultados indica que os gestores tendem a concordar com as afirmativas relacionadas à promoção, transferência e seleção das pessoas com deficiência, o que indica a existência de procedimentos que não as colocam em desvantagem em relação às demais pessoas. No entanto discordam de que tenham sido incluídos nos treinamentos de Brigadas de Incêndio, procedimentos direcionados à evacuação de pessoas com deficiência.

Os resultados encontrados indicam que, apesar de haver uma tendência de concordância em relação às afirmativas relacionadas às práticas de Recursos Humanos, $46 \%$ dos gestores discordam das afirmativas. Esse resultado indica que não existe consenso em relação às questões, quer seja porque elas efetivamente não ocorram, quer seja devido à ausência de divulgação dentro da empresa das práticas de Recursos Humanos destinadas à inserção, resultado que é confirmado pelas entrevistas.

\section{Análise das Relações entre Concepções de Deficiência e Ações de Adequação das Condições e Práticas de Trabalho}

Visando verificar se havia associação entre as médias dos fatores de concepções de deficiência e as médias dos fatores relacionados às ações de adequação das condições e práticas de trabalho, foi realizado o teste rho de Spearman, conforme Tabela 1.

Tabela 1: Correlação de Spearman entre os Fatores de Concepção de Deficiência e os Fatores de Ações de Adequação das Condições e Práticas de Trabalho

\begin{tabular}{lccc}
\hline \multicolumn{1}{c}{ Fatores } & Sensibilização & Adaptações & Práticas de RH \\
\hline 1 - Concepção espiritual & - & - & - \\
2 - Concepção baseada em pressupostos de & - & - & - \\
normalidade & $0,252^{*}$ & - & $0,247^{*}$ \\
3 - Concepção baseada na inclusão & - & - & - \\
4 - Percepção de desempenho & - & - & - \\
5 - Percepção do vínculo & $0,381^{* *}$ & - & - \\
6 - Percepção dos benefícios da contratação & - & - & - \\
7 - Percepção sobre a necessidade de treinamento & & \\
* Indica que a correlação é significante no nível de $0,05$. & & \\
** Indica que a correlação é significante no nível de $0,01$. & & & \\
Fonte: dados da Pesquisa, 2006. & &
\end{tabular}


Quanto à correlação dos fatores, apesar de suas baixas intensidades, observam-se na Tabela 1 indicações acerca do que se explicita a seguir.

1) Quanto mais as pessoas entendem que as condições de trabalho precisam ser acessíveis a todos (adequação das condições e instrumentos de trabalho) - concepção baseada na inclusão - maiores são as atividades de sensibilização realizadas nas unidades da empresa, e vice-versa.

2) Quanto mais as pessoas compartilham da concepção baseada na inclusão, maiores são as adequações das práticas de Recursos Humanos realizadas nas unidades da empresa, e vice-versa.

3) Quanto maior é a percepção dos benefícios da contratação de pessoas com deficiência na empresa, maiores são as atividades de sensibilização realizadas em suas unidades, e vice-versa.

4) Quanto mais os gestores concordam em que as chefias e funcionários não estão preparados para o processo de inserção de pessoas com deficiência (necessidade de treinamento), menos concordam em que as adequações das práticas de Recursos Humanos tenham sido realizadas, e vice-versa. Em suma, a falta de treinamento cria um problema para a inserção de pessoas com deficiência.

\section{Análise da Satisfação em Relação aos Fatores de Qualidade de Vida no Trabalho por parte das Pessoas com Deficiência da Empresa}

No fator referente à satisfação com a remuneração, os resultados encontrados indicam que, apesar de a maioria $(61 \%)$ das pessoas com deficiência estar satisfeita com sua remuneração, existe na empresa uma tendência grande à insatisfação em relação a esse fator, pois o percentual de insatisfeitos é igual a $39 \%$ do total da amostra. Nas entrevistas realizadas, todas as pessoas com deficiência entrevistadas disseram estar satisfeitas com a remuneração, mas que o salário poderia ser melhor. Conforme um funcionário: "Os salários deveriam ser mais condizentes com o peso que a empresa tem no mercado e na sociedade".

No fator satisfação com as condições de trabalho, $88 \%$ das pessoas com deficiência reconhecem o empenho da empresa em adequar as condições de trabalho e os avanços conseguidos nos últimos anos.

No fator satisfação com o uso e desenvolvimento de suas capacidades, os resultados encontrados indicam que as pessoas estão satisfeitas com a relação de adequação entre suas funções e suas capacidades, considerando que existem possibilidades de integrar o planejamento e a execução do trabalho, as informações necessárias para a realização dos trabalhos e existem possibilidades de aplicação dos conhecimentos e habilidades adquiridos. Nas entrevistas, essas informações foram ratificadas. Além disso, foi possível confirmar que as pessoas com deficiência trabalham nas mais diversas atividades da empresa juntamente com as demais pessoas. Não há segregação das pessoas com deficiência em setores separados dos demais funcionários.

No fator satisfação com as oportunidades de crescimento profissional, os resultados encontrados indicam que, apesar de a média geral revelar satisfação com as oportunidades de crescimento profissional oferecidas pela empresa, 35\% dos funcionários estão insatisfeitos com os quesitos constantes nesse fator, e a principal queixa é em relação à falta de eqüidade nos processos de promoção, sendo subestimada a capacidade e/ou o potencial das pessoas com deficiência antes de checar sua capacidade e/ou incapacidade para a tarefa.

No fator satisfação com a integração social na organização, $90 \%$ das pessoas com deficiência estão satisfeitas com sua integração social.

No fator satisfação com os direitos na instituição, os resultados encontrados indicam que $84 \%$ das pessoas com deficiência estão satisfeitas. As sugestões e queixas das pessoas com deficiência foram: que o portador de deficiência tenha acesso às informações sobre as restrições de atividades que possa desempenhar e "treinar os superiores para nos receber, e não tratar-nos como coitados, e, sim, como profissionais". 
Com relação ao fator satisfação com o equilíbrio trabalho e vida, os resultados encontrados indicam que $84 \%$ das pessoas com deficiência estão satisfeitas em relação a esse fator. A sugestão apresentada foi contratar mais funcionários devido à sobrecarga de trabalho existente atualmente na empresa, queixa presente também entre os funcionários não-portadores de deficiência.

No fator satisfação com a relevância do trabalho, os resultados encontrados indicam que, de forma geral, as pessoas estão satisfeitas com esse fator (91\% do total da amostra), o que é corroborado pelas entrevistas, nas quais todos os entrevistados enfatizaram a importância do trabalho na vida deles. Afirmaram que o trabalho é uma possibilidade de demonstrar suas capacidades e de dar contribuições para a sociedade. Disseram também que o trabalho é uma forma de mostrar que não são inválidos e que podem contribuir, ser independentes e úteis. Conforme dito por um portador de deficiência entrevistado: "sem o trabalho não se é feliz por inteiro".

\section{CONCLUSÕES}

De forma geral, a utilização dos construtos de concepções de deficiência, de ações de adequação das condições e práticas de trabalho e de qualidade de vida no trabalho possibilitou uma compreensão mais sistematizada da gestão do trabalho de pessoas com deficiência em uma empresa específica.

Pode-se constatar a realidade de uma empresa que, muito provavelmente, está à frente da maioria das empresas do país em relação a essa dimensão da diversidade, mas que também reconhece suas fragilidades e tem interesse em conhecê-las, o que pode ser verificado na apresentação de seus resultados.

Fazendo uma análise geral das concepções de deficiência presentes na empresa, verifica-se a predominância de um discurso pautado na matriz da inclusão e com ênfase nos fatores da matriz técnica (desempenho, benefícios da contratação e treinamento, principalmente), o que referenda a literatura que indica um deslocamento da preocupação em relação à dimensão social da diversidade para uma dimensão técnica como recurso a ser administrado (Alves \& Galeão-Silva, 2004). A percepção da diversidade como questão social é privatizada pela empresa, que assume em seus princípios de responsabilidade socioambiental seu compromisso social com essa questão, e não apenas cumprindo a lei como obrigação a ser realizada.

Contudo a gestão da diversidade mostra-se complexa, porquanto, apesar do predomínio de concordância com algumas concepções de deficiência, as outras também apareceram na organização, tornando a administração da coexistência de concepções, às vezes, antagônicas, um desafio para a área de Gestão de Pessoas.

Em relação ao construto ações de adequação das condições e práticas de trabalho, verifica-se que, em relação ao fator sensibilização, os resultados revelaram a necessidade de um trabalho mais efetivo em algumas unidades da empresa, visando facilitar a inserção e gestão do trabalho das pessoas com deficiência.

As adaptações são as ações privilegiadas pela empresa nesse processo de gestão da diversidade.

Em relação às práticas de Recursos Humanos, os resultados indicam que a empresa precisa definir basicamente as suas estratégias de treinamento relacionadas à evacuação de área por parte das pessoas com deficiência, garantir a igualdade de oportunidades nos processos de promoção e transferência dessas pessoas e divulgar essas ações entre as gerências.

Em relação aos fatores de qualidade de vida no trabalho, de forma geral, as pessoas com deficiência estão satisfeitas com os aspectos pesquisados. No entanto os fatores relacionados à remuneração e às oportunidades de crescimento profissional indicam insatisfação de mais de $30 \%$ das pessoas com 
deficiência na empresa. Com relação ao salário, pôde-se verificar durante a pesquisa que a empresa não distingue pessoas com e sem deficiência. Contudo as insatisfações manifestadas em relação às oportunidades de crescimento profissional indicam que as pessoas com deficiência percebem diferenças no tratamento destinado a elas nesse processo. Isso parece refletir as concepções de deficiência espiritual (19\% das gerências) e baseada na normalidade (21\% das gerências), ainda presentes na empresa, dando ênfase na deficiência como impedimento ao desempenho e às possibilidades de crescimento profissional.

Um fator ainda não mencionado nas análises diz respeito à satisfação com a garantia dos direitos pela empresa, em que as duas demandas apresentadas pelas pessoas com deficiência (acesso às informações que lhes dizem respeito e tratamento igualitário) confirmam as indicações de procedimentos recomendados pela literatura na área: Agência Européia para Segurança e Saúde no Trabalho, 2004; Morris, 1992; Oliver, 1992; Sassaki, 1999; Thomas, 2004.

Também a análise dos dados permitiu a verificação de algumas correlações entre os construtos concepções de deficiência e ações de adequação das condições e práticas de trabalho. Os dados empíricos confirmaram que a concepção baseada na inclusão está relacionada positivamente com as ações de sensibilização e com as práticas de Recursos Humanos, e vice-versa. Essas constatações têm desdobramento prático, pois se pressupõe também que implementando ações de sensibilização e adequando as práticas de Recursos Humanos, aumenta-se a percepção das pessoas de que o ambiente de trabalho precisa ser acessível a todos. Essas correlações reafirmam o pressuposto de que a maior ou menor adequação de práticas de gestão de pessoas com deficiência (sensibilização e práticas de RH) modifica a relação de forças entre pessoas com e sem deficiência, pois têm uma relação direta com a forma como as pessoas concebem a deficiência na empresa, no caso específico, com a presença da concepção baseada na inclusão.

Verifica-se, ainda, que a percepção dos benefícios da contratação de pessoas com deficiência está associada com as ações de sensibilização, o que implica também que, aumentando-se as ações de sensibilização, aumenta-se esse tipo de percepção entre as pessoas.

Também é importante ressaltar a especificidade do estudo de caso que contempla uma empresa que faz questão de associar seu nome ao de uma organização socialmente responsável e que pretende ser um vetor de transformação social. Isso confirma as conclusões de Hanashiro e Godoy (2004), que afirmam que a questão da gestão da diversidade faz parte de um contexto organizacional específico, que varia de empresa para empresa e que depende de muitos fatores, tais como: definição das políticas e estratégias da empresa junto ao mercado e aos funcionários, capital para investimento em modificações das condições de trabalho e vontade política dos dirigentes.

No entanto esta pesquisa traz para o cenário das investigações um caso de efetivação de uma ação afirmativa - a Lei de Cotas para pessoas com deficiência - e a análise de aspectos relevantes para o desenvolvimento de programas de diversidade que possibilitam beneficiar pessoas que tinham seu direito ao trabalho negado no país.

As pesquisas sobre essa nova realidade nas organizações são necessárias, tanto para criticar as práticas existentes quanto para indicar possibilidades de introduzir outra lógica nas relações de trabalho, a lógica da inclusão. Essa nova lógica tem como premissa substituir a busca por um homem ideal e padronizado pela adequação das condições e práticas de trabalho, de forma a acolher as diferenças. Ainda que a inclusão dessas pessoas mantenha as contradições próprias às relações de trabalho capitalistas, transformando as diferenças em mercadoria e em diferencial competitivo para as organizações, ela abre possibilidades para um ordenamento social menos discriminatório.

Por último, é importante sublinhar que, embora o estudo contemple um caso específico, ele permitiu colocar à prova os construtos de concepções de deficiência e de ações de adequação das condições e práticas de trabalho, demonstrando sua fertilidade tanto para diagnóstico quanto para o planejamento de ações de inserção e gestão do trabalho de pessoas com deficiência, além de demonstrar a capacidade heurística do modelo de análise proposto para a pesquisa. 
Artigo recebido em 02.07.2007. Aprovado em 03.07.2008.

\section{REFERENCIAS BIBLIOGRÁFICAS}

Agência Européia para a Segurança e a Saúde no Trabalho. (2004, julho 07). Garantir a segurança e a saúde dos trabalhadores com deficiência. Facts 53. Recuperado em 24 janeiro, 2005, de http://osha.europa.eu/pt/publications/factsheets/53

Alves, M. A., \& Galeão-Silva, L. G. (2004). A crítica da gestão da diversidade nas organizações. Revista de Administração de Empresas, 44(3), 20-29.

Amiralian, M. L. T. M. (1986). Psicologia do excepcional (Temas básicos de psicologia, Vol. 8). São Paulo: EPU.

Anache, A. A. (1996). O deficiente e o mercado de trabalho: concessão ou conquista? Revista Brasileira de Educação Especial, 2(4), 119-126.

Aranha, M. S. F. (1995). Integração social do deficiente: análise conceitual e metodologia. Temas em Psicologia, 3(2), 63-70.

Barnes, C. (1999). Disability Studies: new or not so new directions? Disability \& Society, 14(4), 577580.

Barnes, C., Mercer, G., \& Shakespeare, T. (2005). Exploring disability: a sociological introduction. Cambridge: Polity Press.

Barnes, C., Oliver, M., \& Barton, L. (2002). Disability studies today. Cambridge: Polity Press.

Batavia, A. I., \& Schriner, K. (2001). The Americans with disabilities act as engine of social change: models of disability and the potential of a civil rights approach. Policy Studies Journal, 29(4), 690-702.

Batista, C. A. M. (2004). Inclusão: construção na diversidade. Belo Horizonte: Armazém de Idéias.

Bianchetti, L. (1998). Aspectos históricos da apreensão e da educação dos considerados deficientes. In L. Bianchetti \& I. M. Freire (Orgs.). Um olhar sobre a diferença: interação, trabalho e cidadania (pp. 21-51). Campinas: Papirus.

Bourdieu, P. (1996). Razões práticas: sobre a teoria da ação. Campinas: Papirus.

Bourdieu, P. (2000). O poder simbólico (3a ed.). Rio de Janeiro: Bertrand Brasil.

Carreira, D. (1997). A integração da pessoa deficiente no mercado de trabalho. In M. T. E. Mantoan (Org.). Integração de pessoas com deficiência: contribuições para a reflexão sobre o tema. São Paulo: Memnon.

Carvalho-Freitas, M. N. (2007). A inserção de pessoas com deficiência em empresas brasileiras. Tese de doutorado, Universidade Federal de Minas Gerais, Belo Horizonte, Minas Gerais, Brasil.

Carvalho-Freitas, M. N., Marques, A. L., \& Scherer, F. L. (2004, setembro). Inclusão no mercado de trabalho: um estudo com pessoas portadoras de deficiência. Anais do Encontro Nacional de Pós-Graduação e Pesquisa em Administração, Curitiba, PR, Brasil, 28. 
Cross, E. Y., Katz, J. H., Miller, E., \& Seashore, E. W. (1994). The promise of diversity. Burr Ridgne, IL: Irwin.

Freund, P. (2001). Bodies, disability and spaces: the social model and disabling spatial organizations. Disability \& Society, 16(5), 689-706.

Goss, D., Goss, F., \& Adam-Smith, D. (2000). Disability and employment: a comparative critique of UK legislation. The International Journal of Human Resource Management, 11(4), 807-821.

Hanashiro, D. M. M., \& Godoy, A. S. (2004, setembro). Um preâmbulo à gestão da diversidade: da teoria à prática. Anais do Encontro Nacional da Associação Nacional de Pós-Graduação e Pesquisa em Administração, Curitiba, PR, Brasil, 28.

Henderson, G., \& Bryan, W. V. (2004). Psychosocial aspects of disability (3rd ed.). Illinois, USA: Charles C. Thomas.

Jamieson, D., \& O’Mara, J. (1991). Managing workforce 2000. San Francisco: Jossey-Bass.

Kamal, D. (2004). Diversity works. Canadian Business, 77(7), 53-55.

Kitchin, R. (1998). "Out of Place", "knowing one's place": space, power and the exclusion of disabled people. Disability \& Society, 13(3), 343-356.

Lancillotti, S. S. P. (2001, outubro). A integração pelo trabalho na sociedade da exclusão. Anais do Encontro Nacional de Pós-Graduação e Pesquisa em Educação, Caxambu, MG, Brasil, 24.

Lüdke, M., \& André, M. E. D. A. (1986). Pesquisa em educação: abordagens qualitativas. São Paulo: EPU.

Malhotra, N. K. (2001). Pesquisa de marketing: uma orientação aplicada (3a ed.). Porto Alegre: Bookman.

Mantoan, M. T. E. (1997). A integração de pessoas com deficiência: contribuições para a reflexão sobre o tema. São Paulo: Memnon.

Mantoan, M. T. E. (2004). O direito à diferença na igualdade dos direitos: questões sobre a inclusão escolar de pessoas com e sem deficiências. In C. A. M. Batista (Coord.). Ética da Inclusão (pp. 94-104). Belo Horizonte: Armazém de Idéias.

Martins, S. M. F. C. (1996). Deficiência física e mercado de trabalho: o ponto de vista do trabalhador deficiente. Consciência, 10(1), 55-70.

Morris, J. (1992). Personal and political: a feminist perspective on researching physical disability. Disability, Handicap \& Society, 7(2), 1-12.

Nkomo, S. M., \& Cox, T., Jr. (1999). Diversidade e identidade nas organizações. In S. R. Clegg, C. Hardy, \& W. R. Nord (Orgs.). Handbook de estudos organizacionais (pp. 334-360). São Paulo: Atlas.

Oliveira, M. H. A. (1993). Núcleos cooperativos: uma perspectiva profissional para o portador de deficiência. Em Aberto, 13(60),106-108.

Oliver, M. (1992). Changing the social relations of research production? Disability, Handicap \& Society, 7(2), 101-114.

Omote, S. (1995). A integração do deficiente: um pseudo-problema científico. Temas de Psicologia, $3(2), 71-83$. 
Omote, S. (1996). Perspectivas para conceituação de deficiências. Revista Brasileira de Educação Especial, 2(4), 127-135.

Pessoti, I. (1984). Deficiência mental: da superstição à ciência. São Paulo: T. A. Queiroz.

Popovich, P. M., Scherbaum, C. A., Scherbaum, K. L., \& Polinko, N. (2003). The assessment of attitudes toward individuals with disabilities in the workplace. The Journal of Psychology, 137(2), 163-177.

Sassaki, R. K. (1999). Inclusão (3a ed.). Rio de Janeiro: WVA.

Schur, L. (2002). The difference a job makes: the effects of employment among people with disabilities. Journal of Economic Issues, 36(2), 339-348.

Silva, O. M. (1993). Uma questão de competência. São Paulo: Memnon.

Stevens, G. R. (2002). Employers' perceptions and practice in the employability of disabled people: a survey of companies in south east UK. Disability \& Society, 17(7), 779-796.

Thomas, C. (2004). How is disability understood? An examination of sociological approaches. Disability \& Society, 19(6), 569-583.

Tregaskis, C. (2002). Social model theory: the story so far... Disability \& Society, 17(4), 457-470.

Walton, R. (1973, Fall). Quality of working life: what is it? Sloan Management Review, pp. 11-21.

Woodhams, C., \& Daniele, A. (2000). Disability and diversity - a difference too far? Personnel Review, 29(3), 402-417. 